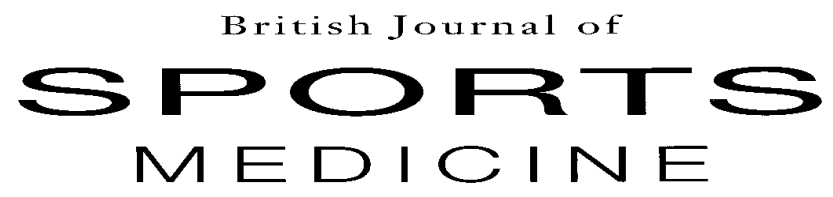

\title{
Editorials
}

Warm up

The world is an amazing place. Those who have just realised that the incoming editor of the British Fournal of Sports Medicine is an Australian must think the end of civilisation has come. The thin end of the wedge and all that. Is it not enough that the Australians are world champions in rugby (both versions), surfing, cricket (both forms-paying and non-paying), and did rather well at the recent Olympics, now the British journal is moving offshore. It may be seen as the Antipodean revenge of England's convict past. Rest assured, there will be no immediate change evident. No Australian flag tastefully draped over the cover nor pictures of Ian Thorpe and his 400 gold medals for swimming. No page 3 pictures à la Rupert Murdoch. The change will be subtle, yet it will define an evolution in the development of the journal.

Domhnall MacAuley, over the past five years, has taken the journal to the dizzy heights of scientific credibility and respectability. To him an enormous debt of gratitude is owed. Àdh mòr, Domnhall.
With the beginning of the new millennium, it is an appropriate time for the journal to spread its wings and reach a global audience. For this reason, much thought went into the process of selecting a new editor. The fact that there was considerable interest in this position from many parts of the world reflects positively both on the journal and its parent, BASEM.

The start of BFSM online is one step in this process of international development. With the advent of the world wide web and email capability, journal editors are no longer limited by geographic boundaries. The electronic horizon is opening rapidly and the BFSM should be at the forefront of this change. The experience of electronic publishing by the BMJ Publishing Group should enable a smooth and rapid transition to this new era. In addition, I expect that electronic manuscript submission and review will be our next development in this line.

Be reassured that change is inevitable. The editor may be antipodean but the journal remains firmly British, albeit with a global outlook.

\section{A journey of a thousand miles begins with a single step}

In a fascinating study recently published in the fournal of Science and Medicine in Sport, Dr Caroline Finch from Deakin University in Melbourne, Australia studied the safety procedures at 64 Australian football clubs. ${ }^{1}$ One of the striking findings was the lack of knowledge of Sports Medicine Australia (SMA) guidelines. For example, when asked whether these clubs followed the SMA infectious disease policy, only $36 \%$ of clubs answered positively with $21 \%$ being totally unaware of the existence of the guidelines. Even more remarkable, given that SMA has had a head and neck injury policy since 1992 , was the fact that only $27 \%$ of football clubs had a head injury policy and of these, only $11 \%$ followed the SMA guidelines when suggesting medical assessment for head injured players. Returning players to sport following concussion was even more interesting, with $30 \%$ of clubs having some sort of guidelines, mostly non-scientific in nature, and just $6 \%$ following the SMA recommendations.

This study exposes a significant problem for sports injury prevention worldwide and in particular, the role of peak administrative bodies. If such sports medicine groups devote time, resources and expertise in developing appropriate guidelines, a crucial aspect of this process must be the dissemination of this information. Having an impressive policy is one thing, but if no one reads it, why bother?
Increasingly, we live in an age where sports medicine practitioners and especially sports trainers desire strict guidelines for the management of sporting injuries. A cookbook approach with a recipe for every disaster. In my own particular area of research-that is, concussion, we have the extraordinary situation of 27 different published management guidelines (none of which have the slightest scientific basis) and yet we cannot agree on a consensus diagnosis of concussion! Most people would be familiar with the three week ban in rugby following a concussion. It was originally instituted to provide a guideline for teams without medical support; this was a laudable aim but let us not pretend that it is scientific. The recent move by the International Rugby Board to provide some flexibility in this regard is a step in the right direction.

Do these various concussion guidelines work? The answer is a resounding, no. In many cases, having a published concussion guideline in your own name is a rite of passage in this field. Forget the science just get a guideline, any guideline. Modify someone else's and republish it in your own name. That saves time even thinking about the process. No wonder athletes and coaches become confused. Mind you, clever athletes (no that's not an oxymoron) can shop around to find a return to sport guideline that suits their needs or bank balances not necessarily their cognitive health. 
How then do we develop useful and meaningful guidelines? Consensus conferences are useful but you need to have the major researchers and interest group represented. Science is important but equally its absence needs to be clearly defined. There is no point dressing up a non-scientific guideline in the respectability of a sports medicine organisation. The American Academy of Neurology concussion guidelines are a case in point. The 'consensus' guidelines were from US-based physicians only, with little direct sports medicine involvement. The spectacle of people involved in that process publicly distancing themselves from the final conclusions demonstrates the potential difficulties in this process. The outcomes were not scientific and what were guidelines rapidly became management 'options'. The proof of the pudding however, lies in the fact that these guidelines have been almost universally ignored. Wide dissemination has no meaning if people don't believe in them.
Next year in November, a consensus conference on concussion is being attempted once again. Driven by the National Hockey League with the assistance of the IOC and FIFA, a scientific program is being developed to try and revisit this area once again. Hopefully the lessons of the past will be learned and the outcome of this meeting will be a useful addition to the field. Keep your eyes on the conference announcements at the back of the journal.

As we move towards a wider evidence base in sports medicine, the role of guidelines should play an increasingly minor role. Understanding the process is the key. As Santa said to the reindeer on Christmas Eve- "Just do it!"

Editor

PAUL MCCRORY

1 Finch CF, Hennessey M. The safety practices of sporting clubs in the City of Hove. F Sci Med Sport 2000;3:9-17. 


\section{Expression of concern about content of which Dr Paul McCrory is a single author}

This paper is authored by Dr Paul McCrory. During 2021 and 2022 there was an investigation by BJSM and BMJ which found that some of his work was the product of publication misconduct. Such misconduct includes plagiarism, duplicate publication, misquotation and misrepresentation in publications in respect of which he was listed as the sole author. ${ }^{1}$ We are placing a notice to readers on all content in relation to which he is identified as the sole author to alert them to the conclusions of our investigation.

(C) Author(s) (or their employer(s)) 2022. No commercial re-use. See rights and permissions. Published by BMJ.

Br J Sports Med 2022;0:1. doi:10.1136/bjsports-2022-106408eoc

D) Check for updates

\section{REFERENCE}

1 Macdonald H, Ragavooloo S, Abbasi K. Update into the investigation of former BJSM editor-in-chief Paul McCrory. Br I Sports Med 2022. 